\title{
COMORBID ANXIETY AND DEPRESSION DISORDERS IN PATIENTS WITH CHRONIC PAIN
}

\author{
Martha Castro ${ }^{1,2}$, Durval Kraychete', Carla Daltro², Josiane Lopes', Rafael Menezes', Irismar Oliveira
}

\begin{abstract}
Objective: To evaluate the frequency of anxiety and depression disorders in patients with chronic pain. Method: Patients receiving care at the pain clinic of the Federal University of Bahia between February 2003 and November 2006. The MINI PLUS - Mini International Neuropsychiatric Interview was used to evaluate the patients and establish psychiatric diagnoses. Results: 400 patients were evaluated mean age was $45.6 \pm 11.37$ years; $82.8 \%$ were female, $17.3 \%$ male; $48.5 \%$ were married; $55.1 \%$ were Catholics; and $40.5 \%$ had only high school education. Of these $29.9 \%$ reported intense pain and $70.8 \%$ reported suffering pain daily. The most frequent medical diagnosis was herniated disc (24.5\%), and $48.5 \%$ of patients had been undergoing treatment at the pain clinic for less than 3 months. Comorbidities found were depressive episodes (42\%), dysthymia (54\%), social phobia (36.5\%), agoraphobia (8.5\%) and panic disorder (7.3\%). Conclusion: Psychiatric comorbidities are prevalent in patients suffering chronic pain.
\end{abstract}

KEY WORDS: pain, chronic disease, depression, anxiety.

\section{Transtornos ansiosos e depressivos em pacientes com dor crônica}

Resumo - Objetivo: Avaliar a freqüência de transtornos ansiosos e depressivos em pacientes com dor crônica. Método: Os pacientes foram avaliados na clínica da dor da Universidade Federal da Bahia entre fevereiro 2003 e novembro 2006. O Mini-plus - entrevista neuropsiquiátrica internacional foi usado para estabelecer diagnósticos psiquiátricos nos pacientes. Resultados: Foram avaliados 400 pacientes com idade média de 45,6 $\pm 11,37$ anos; $82,8 \%$ eram mulheres, homens 17,3\%; 48,5\% eram casados; $55,1 \%$ católicos; e 40,5\% concluíram o segundo grau, $29,9 \%$ relataram dor intensa e 70,8\% relataram sentir dor diariamente. O diagnóstico médico o mais freqüente foi hérnia de disco $(24,5 \%)$, e $48,5 \%$ dos pacientes submeteu-se ao tratamento na clínica da dor por menos de 3 meses. Comorbidades encontradas foram episódios depressivos (42\%), distimia (54\%), fobia social (36,5\%), agorafobia (8,5\%) e transtorno de pânico (7,3\%). Conclusão: Comorbidades psiquiátricas são predominantes em pacientes que sofrem de dor crônica.

PALAVRAS-CHAVE: dor, doença crônica, depressão, ansiedade.

Pain has been one of the major concerns of human beings since the beginning of humanity; however, the interpretation of pain varies from one culture to another'. Chronic pain is defined in the literature as pain that persists beyond the time required to cure the lesion; pain that is continuous and recurrent. It is generally characterized as vague, ill-defined and aggravated by environmental or psychopathological stress factors ${ }^{2}$.

Chronic pain plays a significant role in incapacitating the individual, making it impossible for him/her to per- form the physical or mental activities previously carried out normally. As a result, changes develop in the individual's quality of life in general and disorders and symptoms of anxiety and depression become evident ${ }^{3}$. Studies have shown that patients with chronic diseases and women have a much higher risk of developing psychiatric comorbidities compared to the general population ${ }^{4}$.

Therefore, the objective of this study was to evaluate the frequency of disorders of anxiety and depression in patients with chronic pain.

\footnotetext{
'Pain Clinic, Professor Edgard Santos University Hospital, Federal University of Bahia, Salvador BA, Brazil; ${ }^{2}$ Bahiana School of Medicine and Public Health, Salvador BA, Brazil; ${ }^{3} \mathrm{Head}$ of Psychiatry, Department of Neurosciences and Mental Health, Federal University of Bahia, Salvador BA, Brazil.
}

Received 6 July 2009, received in final form 10 July 2009. Accepted 3 August 2009.

Dra. Martha Moreira Cavalcante Castro - Av. Professor Magalhães Neto 1541 / Lot. Aquarius / Hospital da Bahia / Sala 3014 - $41810-011$ Salvador BA

-Brasil.E-mail: marthamcastro@uol.com.br 


\section{METHOD}

Between February 2003 and November 2006, 400 patients receiving care at the psychology service of the pain clinic at the Federal University of Bahia's Professor Edgard Santos Teaching Hospital were included in this study. A protocol was applied to each patient in which the following variables were evaluated: age, sex, marital status, education level, religion, current occupation, the duration, frequency and intensity of pain, medical diagnosis of the pain, and time and response to treatment. The intensity of the pain was evaluated using a Visual Analogue Scale (VAS) in which the intensity of pain was classified as 0 to 10 , as follows: $0=$ no pain; $1-3=$ mild pain; $4-7=$ moderate pain; and 8-10= extreme pain ${ }^{5-6}$. The Mini International Neuropsychiatric Interview - MINI PLUS, a short standardized diagnostic interview compatible with the criteria of the Diagnostic and Statistical Manual of Mental Disorders (DSM-IV) and the International Statistical Classification of Diseases and Related Health Problems, Revision 10 (ICD-10) was used to evaluate the patients and establish psychiatric diagnoses ${ }^{7-8}$. The Statistical Package for Social Sciences (SPSS), version 9.0 was used to perform the statistical analysis. Quantitative variables were expressed as means \pm standard deviation and qualitative variables as percentages. Student's ttest was used to compare the means of independent samples and the chi-square test to compare proportions. P-values $<0.05$ were considered statistically significant.

\section{RESULTS}

Four hundred patients were evaluated, 331 females $(82.8 \%)$ and 69 males (17.3\%) with a mean age of $45.6 \pm 11.37$ years. As evaluated by Student's t-test, no statistically significant difference in age was found between the groups of male and female participants in the study.

The great majority of patients $(97.1 \%)$ originated from Salvador or from other towns in the state of Bahia; $40.5 \%$ completed only high school education; most (67.7\%) were not actively employed at the time of the interview; and $55.1 \%$ were Catholics. With respect to marital status, 50\% were married or had a stable partner; however, findings revealed that $34.1 \%$ of the women were single, while $75.4 \%$ of the men were married, and this difference between the groups of males and females was statistically significant $(p<0.05)$. With respect to the intensity of pain, $2.3 \%$ of participants had no pain, $9.0 \%$ had mild pain, $28 \%$ reported moderate pain, $29.9 \%$ intense pain and $32 \%$ reported unbearable pain.

The most common medical diagnosis of pain was herniated disc (24.5\%). The majority of patients (70.8\%) reported experiencing pain on a daily basis; however, $48.5 \%$ had been undergoing treatment in the pain clinic for less than three months. With respect to their response to treatment, results revealed that $38 \%$ had achieved moderate relief, $38.5 \%$ little relief and $16.3 \%$ no relief, while $7.3 \%$ had achieved complete relief of the pain.
Table 1. Frequency of current and past mood disorders in the 400 patients receiving care at the pain clinic of the Teaching Hospital between February 2003 and November, 2006 in Salvador, Bahia, Brazil.

\begin{tabular}{lcc}
\hline Mental disorders & $\mathrm{n}$ & $\%$ \\
\hline Current depressive episode & 168 & 42 \\
Current dysthymic disorder & 216 & 54 \\
Past depressive episode & 232 & 58 \\
Past dysthymic disorder & 184 & 46 \\
\hline
\end{tabular}

Table 2. Frequency of anxiety disorders in the 400 patients receiving care at the pain clinic of the Teaching Hospital between February, 2003 and November, 2006, Salvador, Bahia, Brazil.

\begin{tabular}{lcc}
\hline Anxiety disorders & $\mathrm{n}$ & $\%$ \\
\hline Social phobia & 146 & 36.5 \\
Agoraphobia & 34 & 8.5 \\
Panic disorder & 29 & 7.3 \\
Specific phobia & 14 & 3.5 \\
Generalized anxiety disorder & 21 & 5.3 \\
Obsessive-compulsive disorder & 12 & 3.0 \\
Post-traumatic stress disorder & 7 & 1.8 \\
Mixed anxiety and depression & 7 & 1.8 \\
\hline
\end{tabular}

At the time of the interview, the psychiatric disorders found in this sample population (Tables 1 and 2) showed that 168 patients (42\%) had a diagnosis of major depressive episode (MDE), whereas 216 (54\%) had a diagnosis of dysthymic disorder. With respect to the past history of the patients, 232 (58\%) had had an MDE previously, whereas 184 patients (46\%) had had dysthymic disorder. It should be noted, however, that frequently more than one comorbid psychiatric disorder was found in the same individual.

Anxiety disorders constitute the most frequent comorbidities in patients with chronic pain, the most frequent diagnosis being social phobia $(n=146)$, (Table 2). Other mental disorders were evaluated according to diagnostic category and the following disorders were identified: hypochondria ( $n=43 ; 10.8 \%$ ), body dysmorphic disorder $(n=41$; $10.3 \%$ ), premenstrual dysphoric disorder with dysmenorrhea ( $n=23 ; 5.8 \%)$, psychotic disorder ( $n=19 ; 4.8 \%$ ), alcohol abuse/addiction ( $n=14 ; 3.5 \%$ ) and eating disorder (bulimia) $(n=9 ; 2.3 \%)$. In addition, a risk of suicide was detected in a high percentage of participants ( $n=106 ; 26.5 \%$ ), 51 of these patients (48\%) being classified as low risk, 11 (10\%) as moderate risk and $44(42 \%)$ as having a high risk of suicide.

\section{DISCUSSION}

Evaluation of the psychiatric profile of these patients 
with chronic pain reflects the significance of the data acquired from this population in the ten years in which the pain clinic has been operating and the importance of evaluating the prevalence of the psychiatric symptoms and disorders found in this population.

The characteristics of this sample population are compatible with data from other studies published in the literature in that patients tended to be older, there was a greater prevalence of female patients, and herniated disc was the most common diagnosis of pain'. The majority of the patients were unable to fulfill their professional obligations at the time of the interview, which is in agreement with other findings with respect to the limiting nature of pain'. The social repercussions of pain reflect the impact this symptom has on the life of the individual, and the consequent changes in his/her quality of life and in the ability of patients to carry out physical, intellectual, psychological and professional activities ${ }^{10}$. The majority of patients $(70.8 \%)$ reported experiencing pain on a daily basis; and $48.5 \%$ had been undergoing treatment at the pain clinic for less than three months. This may explain the findings that response to treatment was described as slight relief by $38.5 \%$ of patients, moderate relief by $38 \%$, no relief at all by $16.3 \%$ and full relief of pain by $7.3 \%$ of study participants. The duration of treatment was obviously insufficient to achieve a satisfactory response with respect to the relief of chronic pain in the majority of cases. On the other hand, the relatively high rate of improvement may reflect the efficacy of the services provided by this clinic and the work of the multidisciplinary team. Those patients who reported no improvement may form part of a group in which therapeutic results would only be achieved after an extended period of treatment. The finding that the MINI-PLUS identified two or more psychiatric disorders in a substantial proportion of the patients in this study was relevant, and suggests that this is a population with many comorbid psychiatric disorders. This fact indicates a need for further studies to evaluate this population and establish psychiatric diagnoses in patients with chronic pain, since this finding of comorbidity would appear to interfere in pain control ${ }^{17-12}$.

The results of the application of the MINI-PLUS confirm findings in the literature showing the strong association between chronic pain and psychiatric disorders ${ }^{13}$. In this sample population, a high prevalence of mood and anxiety disorders was found, confirming various reports in the literature that these disorders are closely associated with chronic pain. The high number of patients currently suffering from a depressive episode may be related to the constant presence of pain in the daily life of these patients or to the temporary relief from the pain, as well as to all the repercussions resulting from changes in areas such as work, sexuality, social life, leisure, self-esteem and many other areas affected by this chronic illness. Analysis of past depressive episodes show that $58 \%$ of this sample population had already suffered from some form of psychiatric disease prior to the onset of the current state of pain, suggesting that lack of adequate pharmacological treatment for this mental disorder in these patients may affect their response to the treatment for pain ${ }^{14}$. Psychiatric evaluation of this population would be useful for the screening of patients who should be submitted to more invasive techniques such as anesthetic block and acupuncture. With respect to the high rate of anxiety disorder found in this sample population, results show a predominance of social phobia, agoraphobia and specific phobia, which, taken together, affect a total of $48.5 \%$ of participants. This is to be expected from the profile of these patients who, due to the constant presence of pain, begin to adopt avoidance postures, either because they fear a return of the pain or because of their difficulty in being understood in their social environment ${ }^{15}$. A high proportion of patients in this study were evaluated as being at risk for committing suicide ( $n=106 ; 26.5 \%$ ). Since this is a population that has suffered pain for many years and has sought relief from this state of pain through numerous instruments and therapeutic techniques, when this objective is not achieved, a response of "little will to live" may be generated, reflecting the low quality of life in this population. Moreover, since this is a population of patients with many comorbid psychiatric conditions, a high incidence of pain, numerous limitations to their normal daily routine and difficulties that have to be faced daily, it becomes essential to fully evaluate the risk of suicide in this population ${ }^{16}$.

This cross sectional study was carried out in this sample population with the objective of classifying and evaluating the patients receiving care at this pain clinic. In conclusion, the sociodemographic data of these patients, as well as the findings with respect to the evaluation of pain and the frequency of comorbid psychiatric disorders, were in agreement with those reported in the literature, confirming the recommendation that these are patients who require further interventions and mental healthcare in order to achieve relief from their pain.

\section{REFERENCES}

1. Teixeira MJ, Okada M. Dor: evolução histórica dos conhecimentos. In: Teixeira MJ, Braum JL Filho, Márquez JO, Yeng LT (Eds). Dor: contexto multidisciplinar. Curitiba 2003:15-51.

2. Paquet C, Kergoat MJ, Dubé L. The role of everyday emotion regulation on pain in hospitalized elderly: insights from a prospective within-day assessment. Pain 2005;115:355-363.

3. Gallagher RM, Moore P, Chernoff I. The reliability of depression diagnosis in chronic low back pain: a pilot study. Gen Hosp Psychiatry 1995; 17:399-413.

4. Raphael KG, Janal MN, Nayak S, Schwartz JE, Gallagher RM. Psychiatric comorbidities in a community sample of women with fibromyalgia. Pain 2006;124:117-125.

5. Huskisson EC. Measurement of pain. Lancet 1974;2:1127-1131. 
6. Pimenta CAM, Cruz DALM, Santos JLF. Instrumentos para avaliação da dor: o que há de novo em nosso meio. Arq Bras Neurocir 1998;17:15-24.

7. Amorim P. Mini International Neuropsychiatric Interview (MINI): validação de entrevista breve para diagnóstico de transtornos mentais. Rev Bras Psiquiatr 2000;22:106-115.

8. Lecrubier Y, Sheehan DV, Weiller E, et al. The Mini International Neuropsychiatric Interview (MINI), A short diagnostic structured interview: reliability and validity according to the CIDI. Eur Psychiatric 1997;12: 224-231.

9. Teixeira MJ. Anatomia e fisiologia das unidades nociceptivas e supressoras da dor. In: Teixeira MJ, Braum JL Filho, Márquez JO, Yeng LT (Eds). Dor: contexto multidisciplinar. Curitiba, Maio 2003:119-146.

10. Nicassio PM, Moxham EG, Schuman CE, Gevirtz RN. The contribution of pain, reported sleep quality, and depressive symptoms to fatigue in fibromyalgia. Pain 2002;100:271-279.
11. Averill PM, Novy DM, Nelson DV, Berry LA. Correlates of depression in chronic pain patients: a comprehensive examination. Pain 1996;65: 93-100.

12. Eisendrath SJ. Psychiatric aspects of chronic pain. Neurology 1995; 45(Suppl):S26-S34.

13. Juang KD, Wang SJ, Fuh JL, Lu SR, Su TP. Comorbidity of depressive and anxiety disorders in chronic daily headache and its subtypes. Headache 2000; 40: 818-823.

14. Ciaramella A, Grosso S, Poli P et al. When pain is not fully explained by organic lesion: a psychiatric perspective on chronic pain patients. Eur J Pain 2004;8:13-22.

15. Loduca A. Eu e minha dor: convivendo com um processo crônico. Dissertação mestrado. Pontifícia Universidade Católica de São Paulo; 1998.

16. Fisher BJ, Haythornthwaite JA, Heinberg LJ, Clark M, Reed J. Suicidal intent in patients with chronic pain. Pain 2001;89:199-206. 